\title{
Evaluation of the Effects of Photobiomodulation of Low- Level Laser on Total Thickness Burn Induced in Animal Model
}

Maisa Ribeiro ${ }^{1(D)}$, Kamylla Caroline Santos ${ }^{2}$ (D), Mathias Rezende Macedo ${ }^{3}$ (D), Gustavo Albertini de Souza $^{3}$ (D), Francisco Inácio de Assis Neto ${ }^{3}{ }^{(D)}$, Marcelo Monteiro de Castro Almeida ${ }^{4}$, Júlia de Miranda Moraes ${ }^{5}$ (D), Gustavo Henrique Marques Araujo 6 (iD), Valcinir Aloísio Scalla Vulcani 6,*iD

1 PhD student in Animal Science, School of Veterinary and Animal Science, Federal University of Goiás, Goiânia, Goiás, Brazil; maisaribeiro22@outlook.com (M.R.);

2 Master student in Animal Bioscience, Federal University of Jataí, Jataí, Goiás, Brazil; kamyllacarolinefisio@ gmail.com (K.C.S.);

3 Medical Student, Health Sciences Academic Unit, Federal University of Jataí, Jataí, Goiás, Brazil; mathias.macedo@hotmail.com (M.R.M.); gustavoalbertini.5@gmail.com (G.A.S.); frasciscoinacio@gmail.com (F.I.A.N.);

4 Medical Student, Health Sciences Academic Unit, University Center of Mineiros, Mineiros, Goiás, Brazil; marcelofisio@live.com (M.M.C.A.);

5 Adjunct Professor, Medical Course, Health Sciences Academic Unit, Federal University of Jataí, Jataí, Goiás, Brazil; mmjulia.edu@gmail.com (J.M.M.);

6 Adjunct Professor, Veterinary Medicine Course, Agricultural Sciences Academic Unit, Federal University of Jataí, Jataí, Goiás, Brazil. gustavoaraujovet@gmail.com (G.H.M.A.); aloisiosv@ hotmail.com (V.A.S.V.);

* Correspondence: aloisiosv@ hotmail.com (V.A.S.V.);

Scopus Author ID 24473867000

Received: 15.03.2021; Revised: 28.04.2021; Accepted: 5.05.2021; Published: 18.06.2021

Abstract: Aim study was to evaluate the effects of low-power laser photobiomodulation (LBP) in thirddegree burns induced in an animal model. Forty Wistar rats (Ratus norvegicus albinus) were used, females weighing between 200 and 300 grams, randomly divided into a control group $(\mathrm{GC}=20)$ and a laser-treated group $(\mathrm{DL}=20)$. A $1 \mathrm{~cm}^{2}$ third-degree burn injury was performed on the back of each animal after trichotomy and followed by surgical debridement 24 hours after induction. In the treated group (LBP) a laser was applied at a wavelength of $660 \mathrm{~nm}$, a power of $27 \mathrm{~mW}$ and an average irradiance of $0.954 \mathrm{~W} / \mathrm{cm} 2$ at five points of the wound. The total fluency was 350 Joules $/ \mathrm{cm} 2$ and application of 5 Joules per wound. Biopsy fragments were collected on days 3, 7, 15 and 21 post-injury for macro and microscopic analysis using the techniques of Hematoxylin and Eosin (HE), Gomori's Trichrome (TG) and Picrosirius red. The results were evaluated by Tukey's Test and Analysis of Variance (ANOVA), Kruskal-Wallis Test (non-parametric) and T-paired Test. The healing process evaluated by morphometry showed a relative statistical difference between the CG and LBP groups. Histopathological analysis showed a decrease in the inflammatory infiltrate, angiogenesis, synthesis of granulation tissue and collagen deposition, increased fibroblasts, matrix organization, and reepithelization of the lesion. Thus, low-power laser photobiomodulation can contribute to the wound repair process efficiently.

Keywords: healing; photobiomodulation; laser therapy; regenerative medicine.

(C) 2021 by the authors. This article is an open-access article distributed under the terms and conditions of the Creative Commons Attribution (CC BY) license (https://creativecommons.org/licenses/by/4.0/). 


\section{Introduction}

Total thickness burns are considered deep injuries that involve the dermis and reach subcutaneous tissues destroying the epithelial attachments, nerves and blood vessels, which can reach muscle and bone tissue [1]. It is estimated that millions of people are affected by burns annually, and about 1 in 10 affected patients require hospitalization [2-5].

These healing processes have complex physiological mechanisms and involve the inflammation, proliferation, and cell maturation phases. Each stage of the tissue repair process has specific and complementary fundamental characteristics that differentiate them [6]. In cases of deregulation of the mechanisms involved, sequelae with a high prevalence of morbidity, functional disability and aesthetic damage may occur in patients with severe burns $[1,3,5,7]$.

Conventionally, the therapeutic approach seeks to prevent infectious processes and remove necrotic tissues. However, several methods, such as low-power laser photobiomodulation (LBP), have been shown to accelerate healing and prevent morphophysiological tissue impairment $[5,8,9]$.

The biomodulatory effect of LBP can be observed mainly in the inflammatory phase. Some authors have demonstrated that laser therapy is able to decrease the number of inflammatory cells, increase angiogenesis, stimulate the differentiation of myofibroblasts, increase the proliferation of epithelial cells and collagen synthesis, contributing to better healing of skin lesions [10-13]. Among those involved in photobiomodulation by LBP, light is able to promote action on prostaglandins (PG) by changing intracapillary hydrostatic pressure and increasing the absorption of interstitial fluids, decreasing edema [14,15]. In addition, the laser promotes vasodilation, which facilitates the migration of polymorphonuclear cells and monocytes, promotes reabsorption of fibrinous exudate and increases the rate of cell division [16].

In addition, the photoelectric effect also contributes to ionic balance in cells, indirectly stimulating the increase in the synthesis of adenosine triphosphate (ATP), favoring cell vitality and the reorganization of its functions [17,18]. Furthermore, LBP blocks painful transmission between sensory neurons, increasing new blood vessels, decreasing inflammation and bleeding $[19,20]$.

In this sense, the present study aimed to evaluate the effects of a low-power laser on the healing process of skin wounds by full-thickness burns in rats.

\section{Materials and Methods}

The study was conducted at the Federal University of Jataí and Centro Universitário de Mineiros (UNIFIMES, Mineiros-GO) after approval by the Ethics Committee on the Use of Animals at the Federal University of Goiás (CEUA-UFG) (protocol 087/2016). Forty healthy female animals of the species Ratus norvegicus albinus (Wistar lineage), weighing between 300 and 350 grams, were distributed three animals per cage with autoclaved wood shavings and exchanged two to three times a week, fed with food and water ad libitum.

The groups of animals were randomly distributed in two groups, four biopsy moments $(3,7,14$, and 21 days post-lesion) and five repetitions, being: control group $(n=20)$ and low power laser group (LBP - $\mathrm{n}=20$ ), with the application of LBP in lesions. 


\subsection{Animal handling and induction of lesions.}

The animals were anesthetized according to the protocols of Kawano et al. [21]. Preanesthetic agents (Diazepam, 2.5 to $5 \mathrm{mg} / \mathrm{kg}$, IP) were used to reduce management and anesthetic stress $(0.01 \mathrm{~mL} / \mathrm{g}$ solution of $10 \%$ Ketamine and $2 \%$ Xylazine, IP) followed by trichotomy $3 \mathrm{~cm}^{2}$ in the dorsal region. Then, third-degree burn injuries were induced in the dorsal region of the animals. For this purpose, two $5 \mathrm{ml}$ syringes were used transversally coupled by a two-outlet tap and containing water at $95^{\circ} \mathrm{C}$, placed in direct contact with the epilated skin through the opening of one of the syringes forming a $1 \mathrm{~cm}^{2}$ lesion. After the procedures, analgesia was performed using tramadol $(0.3 \mathrm{mg} / \mathrm{kg})$ subcutaneously, administered every 12 hours, for three days, later replaced by tramadol $(1-2 \mathrm{mg} / \mathrm{mL})$ in the animals' water for more than four days. The experimental procedures were performed in an environment separate from the maintenance room and the animals' constant eye lubrication was performed to reduce stress and guarantee well-being. After 24 hours of lesion induction, the necrotic tissue was removed by means of surgical debridement and an occlusive dressing (Tegaderm ${ }^{\mathrm{TM}}$ ) was used in all animals.

\subsection{Low power laser application.}

Laser therapy of the lesions was performed using the Photon Laser III device (DMC Equipamentos), with a wavelength of $660 \mathrm{~nm}, 27 \mathrm{~mW}$ of useful optics power, and an average irradiance of $0.954 \mathrm{~W} / \mathrm{cm} 2$. Laser therapy was performed by a punctual method in four $1 \mathrm{~cm}$ equidistant sites on the edge of the lesions and an application to the central wound bed. LBP fluency ranged from 70 Joules $/ \mathrm{cm}^{2}$ to 35 Joules $/ \mathrm{cm}^{2}$ (per point) at the edges and wound bed, respectively, with a total deposited fluency of 350 Joules $/ \mathrm{cm}^{2}$. According to parameters established in the laser, the application time in both regions was 10 seconds with energy deposited of 1 Joule per point. LBP applications started 24 hours after injury induction with daily frequency until the period defined by the biopsy time of $3,7,14$ and 21 days post-injury.

\subsection{Macroscopic analysis of lesions.}

On the same days of LBP, macroscopic aspects were analyzed in the lesions and recorded on a digital machine coupled to support positioned $20 \mathrm{~cm}$ away from the lesion, according to Lamaro et al. (2019) [1]. Parameters such as inflammation, necrosis, granulation tissue, re-epithelization and evolution of the scar were evaluated. The wound area was analyzed with the semi-automatic software Image Processing and Analysis in Java, version 1.44 (Image J, NIH, USA).

\subsection{Biopsies and microscopic analysis.}

The groups were submitted to four biopsy moments: 3, 7, 15 and 21 days after the injury was induced. After this period, the animals were euthanized, and tissue was removed from the lesion place. Biopsy fragments collected were submitted to different staining techniques. The slides stained with HE were analyzed to identify the intensity of vascular and fibroblastic proliferation, tissue necrosis, crust formation, edema, inflammatory cell infiltrate (polymorphonuclear or mononuclear), reepithelization (evaluated for the extent and thickness of the epithelial layer and keratinization), formation of granulation tissue, organization of the extracellular matrix of the dermis and the presence of hair follicles and sebaceous glands. The tissue repair was analyzed in the slides stained by TG for collagen deposition, formation of 
granulation tissue, reorganization of the extracellular matrix, differentiation of the superficial and deep dermis (loose connective tissue - light blue and dense - dark blue) and the presence of hair follicles and sebaceous glands. Microscopic results of HE and TG staining were expressed in scores from zero to four, being: score 0 (absent); score 1 (up to 25\% of the fragment); score 2 (between 25 and $50 \%$ of the fragment); score 3 (between $50 \%$ and $75 \%$ of the fragment); and score 4 (from $75 \%$ to $100 \%$ of the fragment). The measurement values of the areas were expressed in numerical values for statistical analysis of the data.

Picrosirius red staining analyzed in polarized light microscopy (20x objective) allowed to evaluate of the density of collagen determined by the area marked in green (type III collagen) or reddish-yellow (type I collagen). The photomicrographs obtained in an objective 20X of the Picrosirius red color were analyzed in optical density and converted into pixels, using the semiautomatic software Image J, version 1.44 (NIH, USA).

\subsection{Statistical analysis.}

The morphometric data were submitted to the Tukey test and the analysis of variance (ANOVA) to measure the level of significance. Histopathological variables by HE were analyzed by Kruskal-Wallis non-parametric test. Collagen density stained by TG and Picrosírius red were analyzed together, using the Tukey-Anova test and the T-Paired test. Statistically, the significance level of 5\% (p 0.05) was used for all analyzes with the Sigma Stat 2.3 software.

\section{Results and Discussions}

\subsection{Results.}

The morphometric results (Table 1) demonstrated a significant reduction $(\mathrm{p}<0.01)$ in the size of the wounds in the treated group in relation to the p-control group after 15 days. In the LBP, this reduction can already be seen in seven days.

Table 1. Average in $\mathrm{cm}^{2}$ of the morphometric measurements of the wounds, in the control and LBP groups, at 3,

7,15 , and 21 days after the burn lesions in rats.

\begin{tabular}{c|c|c|c|c} 
ANALYZED GROUPS & 3 DAYS & 7 DAYS & 15 DAYS & 21 DAYS \\
\hline CONTROL GROUP & $1.296^{\mathrm{Aa}}$ & $1.668^{\mathrm{ACc}}$ & $0.193^{\mathrm{BDb}}$ & $0.246^{\mathrm{BDb}}$ \\
\hline LBP & $1.696^{\mathrm{Aa}}$ & $0.63^{\mathrm{Bb}}$ & $0.348^{\mathrm{Bb}}$ & $0.238^{\mathrm{Bb}}$
\end{tabular}

Note. Morphometric analysis of the lesion area by software Image $\mathbf{J}$ version 1.3.1. The significant difference between groups by Tukey and ANOVA tests ( $\mathrm{p}$ 0.05) (lower case letters in the column). The significant difference between the days of the group by the Tukey and ANOVA tests (p 0.05) (capital letters on the same line).

Healing of the lesion observed macroscopically showed an important difference between the groups in 7 days after the induction (Figure 1). In addition, the images demonstrate a marked reduction, in a shorter period, of the size of the wounds in the treated group in relation to the control.

Through histopathological analysis with Hematoxylin and Eosin (Table 2 and Graph $1,2)$, it was possible to observe significant differences in the healing process's evolution. Both groups showed a significant reduction in the necrotic process, with no significant difference between the groups, hemorrhage and edema within 7 days, with the absence of these events within 15 days after the injury. However, the average edema scores were higher in the CG, 
although there was no statistical difference. The crust evaluation did not result in a significant difference between the groups, despite the formation of crusts in the CG in relation to the LBP.

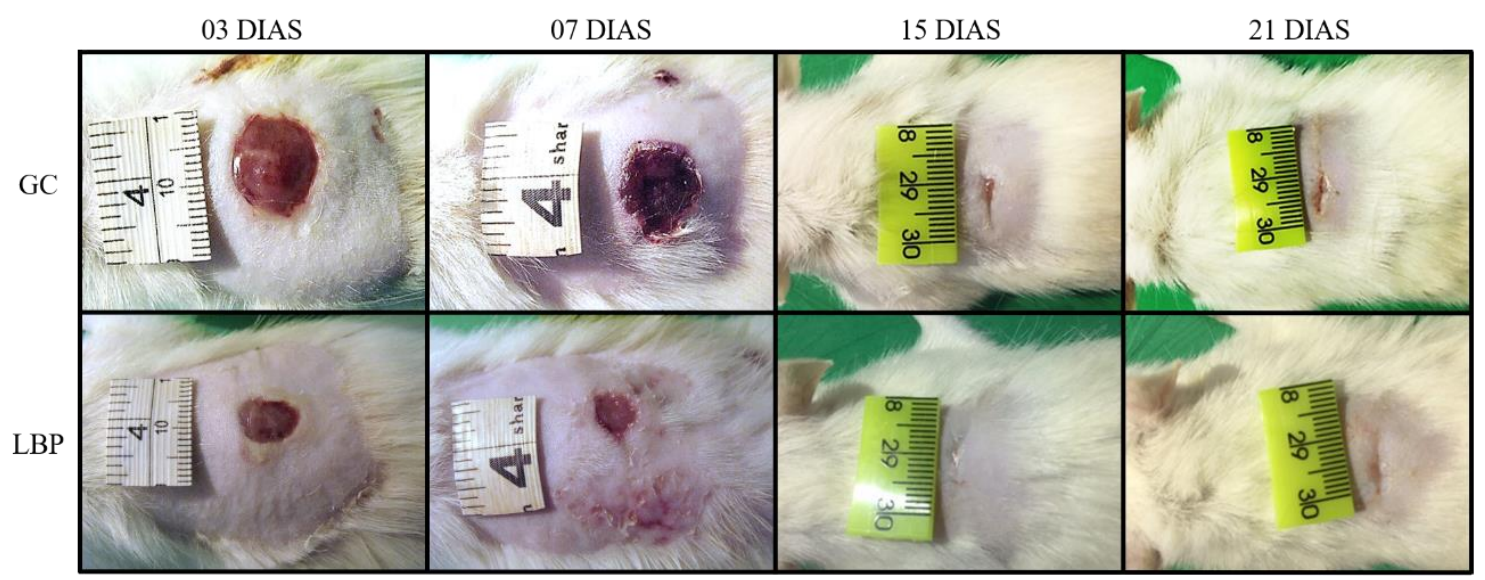

Figure 1. Photos of the third-degree burn lesions on the biopsy day of each group. GC = control group; LBP = group treated with low power laser.

Table 2. Average score (0 to 4 ) of the histopathological results by HE staining of the control and LBP groups at the time of biopsy 3, 7, 15 and 21 days after induction of burn-in rats.

\begin{tabular}{|c|c|c|c|c|c|}
\hline PARAMETERS & & A 3 DAYS & A 7 DAYS & A 15 DAYS & A 21 DAYS \\
\hline \multirow[t]{2}{*}{ Necrosis } & GC & $2.8^{\mathrm{Aa}}$ & $0.4^{\mathrm{Aa}}$ & $0^{\mathrm{Ba}}$ & $0^{\mathrm{Ba}}$ \\
\hline & LBP & $2.4^{\mathrm{Aa}}$ & $0.8^{\mathrm{Aa}}$ & $0^{\mathrm{Ba}}$ & $0^{\mathrm{Ba}}$ \\
\hline \multirow[t]{2}{*}{ Bleeding } & GC & $2^{\mathrm{Aa}}$ & $1^{\mathrm{Aa}}$ & $0^{\mathrm{Ba}}$ & $0^{\mathrm{Ba}}$ \\
\hline & LBP & $2.2^{\mathrm{Aa}}$ & $1.2^{\mathrm{Aa}}$ & $0^{\mathrm{Ba}}$ & $0^{\mathrm{Ba}}$ \\
\hline \multirow[t]{2}{*}{ Edema } & GC & $3.4^{\mathrm{Aa}}$ & $1.4^{\mathrm{Aa}}$ & $0^{\mathrm{Ba}}$ & $0^{\mathrm{Ba}}$ \\
\hline & LBP & $2.2^{\mathrm{Aa}}$ & $0.6^{\mathrm{Aa}}$ & $0^{\mathrm{Aa}}$ & $0^{\mathrm{Aa}}$ \\
\hline \multirow[t]{2}{*}{ Polymorphonuclear Infiltrate } & GC & $2.8^{\mathrm{Aa}}$ & $2.2^{\mathrm{Aa}}$ & $0.4^{\mathrm{Aa}}$ & $0^{\mathrm{Ba}}$ \\
\hline & LBP & $3.2^{\mathrm{Aa}}$ & $1.2^{\mathrm{Aa}}$ & $0^{\mathrm{Ba}}$ & $0^{\mathrm{Ba}}$ \\
\hline \multirow[t]{2}{*}{ Mononuclear Infiltrate } & GC & $3.2^{\mathrm{Aa}}$ & $3^{\mathrm{Aa}}$ & $3.2^{\mathrm{Aa}}$ & $1^{\mathrm{Aa}}$ \\
\hline & LBP & $3.2^{\mathrm{Aa}}$ & $3.8^{\mathrm{Aa}}$ & $2.2^{\mathrm{Aa}}$ & $2.4^{\mathrm{Aa}}$ \\
\hline \multirow[t]{2}{*}{ Angiogenesis } & $\mathrm{GC}$ & $1^{\mathrm{Aa}}$ & $2^{\mathrm{Aa}}$ & $1.6^{\mathrm{Aa}}$ & $1^{\mathrm{Aa}}$ \\
\hline & LBP & $1.8^{\mathrm{Aa}}$ & $3^{\mathrm{ABa}}$ & $1^{\mathrm{ACa}}$ & $0.8^{\mathrm{ACa}}$ \\
\hline \multirow[t]{2}{*}{ Crust } & GC & $0.8^{\mathrm{Aa}}$ & $2.4^{\mathrm{Aa}}$ & $0^{\mathrm{Aa}}$ & $0^{\mathrm{Aa}}$ \\
\hline & LBP & $0.8^{\mathrm{Aa}}$ & $0.6^{\mathrm{Aa}}$ & $0^{\mathrm{Aa}}$ & $0^{\mathrm{Aa}}$ \\
\hline \multirow[t]{2}{*}{ Granulation Tissue } & GC & $1^{\mathrm{Aa}}$ & $2^{\mathrm{Aa}}$ & $2.4^{\mathrm{Aa}}$ & $3.25^{\mathrm{Aa}}$ \\
\hline & LBP & $1^{\mathrm{Aa}}$ & $2.8^{\mathrm{Aa}}$ & $4^{\mathrm{Ba}}$ & $4^{\mathrm{Ba}}$ \\
\hline \multirow[t]{2}{*}{ Fibroblasts } & GC & $1.2^{\mathrm{ACa}}$ & $1.8^{\mathrm{ACa}}$ & $3^{\mathrm{ACa}}$ & $3^{\mathrm{BDa}}$ \\
\hline & LBP & $2.2^{\mathrm{Aa}}$ & $3.2^{\mathrm{Aa}}$ & $3.4^{\mathrm{Aa}}$ & $3.6^{\mathrm{Aa}}$ \\
\hline \multirow[t]{2}{*}{ Reepithelization } & GC & $0^{\mathrm{Aa}}$ & $0.6^{\mathrm{Aa}}$ & $3.6^{\mathrm{Aa}}$ & $4^{\mathrm{Ba}}$ \\
\hline & LBP & $0^{\mathrm{Aa}}$ & $2.2^{\mathrm{Aa}}$ & $3.8^{\mathrm{Ba}}$ & $4^{\mathrm{Ba}}$ \\
\hline
\end{tabular}

Note. Score 0: absent; score 1: up to 25\%; score 2: between 25 and 50\%; score 3: between $51 \%$ and $75 \%$; and score 4: from $76 \%$ to $100 \%$. Different lower case letters in the same column for the same parameter indicate the existence of a significant difference between the groups by the Kruskal-Wallis test $(p<0.05)$. Different capital letters on the same line indicate a significant difference between the days of the group using the Kruskal-Wallis test $(\mathrm{p}<0.05)$.

Regarding mononuclear and polymorphonuclear inflammatory infiltrates, there was no significant difference between groups. There was a progressive reduction of polymorphonuclear cells more pronounced in the treated group, although there was no significant difference. The number of mononuclear cells was maintained for up to 15 days, showing a reduction after 21 days for the $\mathrm{CG}$ and a reduction of 15 days for the LBP. 


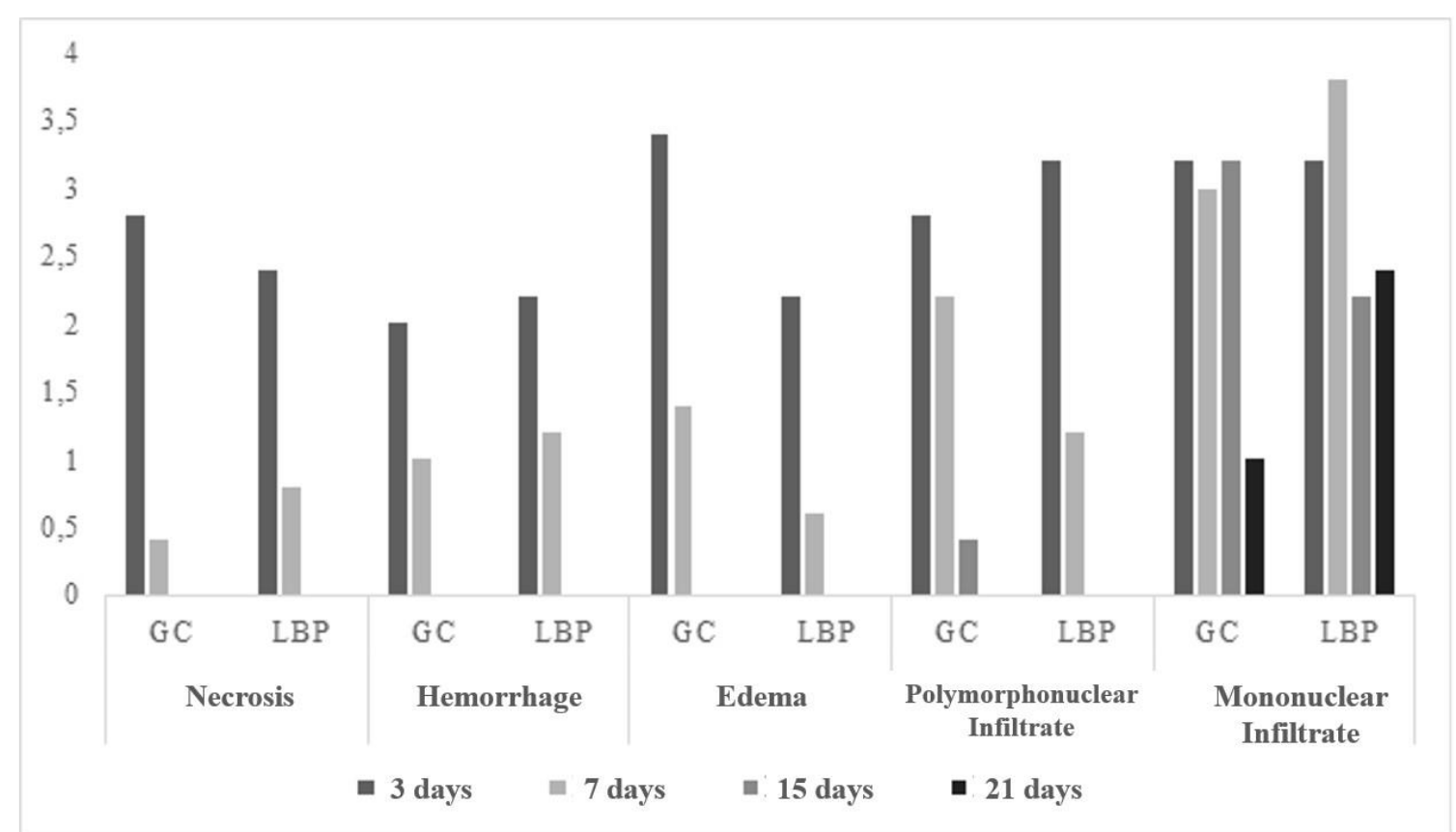

Chart 1. Average histological scores assessed by HE staining in third-degree burn lesions in rats. Scores from 0 to 4, being: score 0: absent; score 1: up to 25\%; score 2: between 25 and 50\%; score 3: between $51 \%$ and $75 \%$; and score 4: from $76 \%$ to $100 \%$. GC: Control Group and LBP: group treated with Low Power Laser.

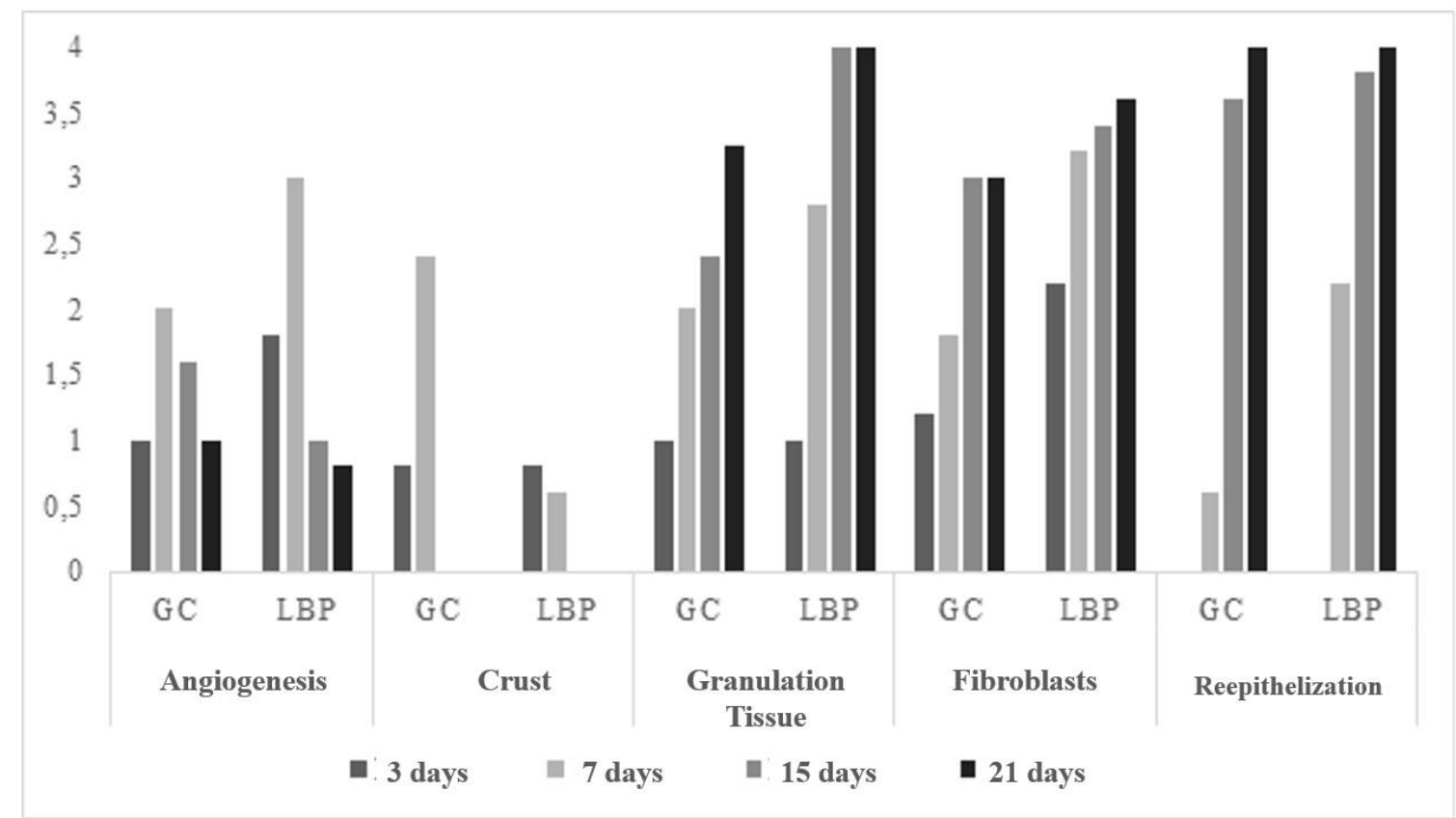

Chart 2. Histological scores assessed by HE staining in third-degree burn lesions in rats. Scores from 0 to 4 , being: score 0: absent; score 1: up to 25\%; score 2: between 25 and 50\%; score 3: between 51\% and 75\%; and score 4: from $76 \%$ to $100 \%$. GC: Control Group and LBP: group treated with Low Power Laser.

Angiogenesis was more intense in the groups treated during the inflammatory phase until the 7 th day, with a progressive decrease from the 15th day. There was also a greater increase in granulation tissue in the LBP group. Although both groups showed a progressive increase in this tissue during the late healing phase, it is observed that the development was more accelerated in the treated group. It is important to note that an average score of 4 was attributed to the LBP at 15 days, while for the CG, an average score was 2.4 at 15 days and 3.25 at 21 days. 


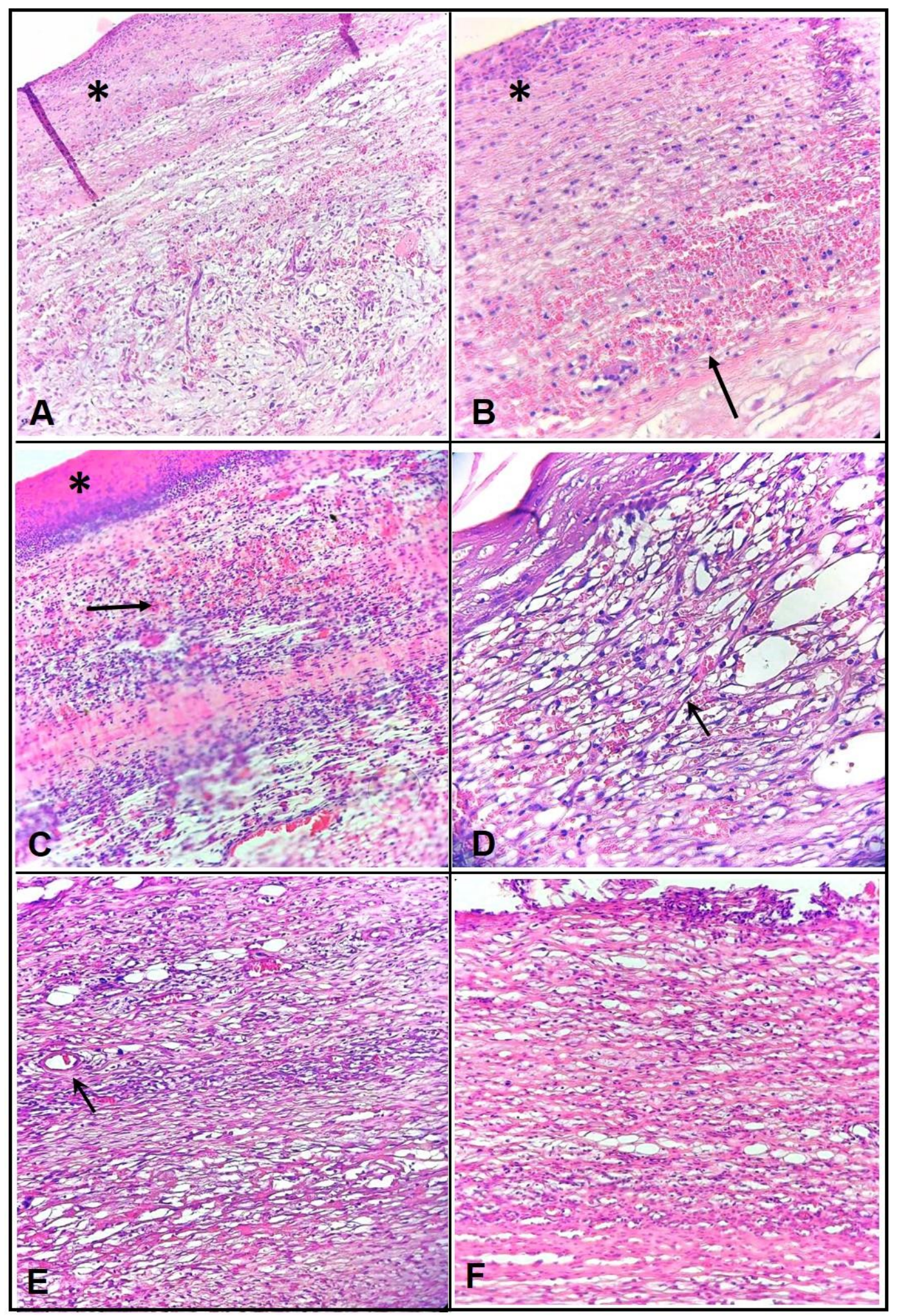

Figure 2. Skin lesions from third degree burns in rats - Photomicrograph with HE stain. A - GC 3 days, intense crust (asterisk) and great tissue disorganization, 10x; B - CG 3 days, intense crust (asterisk) and hemorrhage (black arrow), 20x; C - LBP group 3 days, intense crust (asterisk) and hemorrhage (black arrow), 20x; D - GC 7 days, area with new vessels (black arrow), 20x; E and F = LBP group 7 days, intense formation of new vessels (black arrow), infiltration of mononuclear cells and fibroblasts with greater deposition of extracellular matrix, 20x.

The proliferation of fibroblasts followed the same pattern of occurrence in the lesions, that is, a greater number of cells in the LBP group from the 7 th day of injury. Next, the formation of the epithelium was observed from the 7th day on in both groups. However, a significant difference was observed between the groups of 3 days in relation to the groups of 
15 and 21, with greater thickness of the layer and extension of the epithelium in the treated groups in relation to the controls.

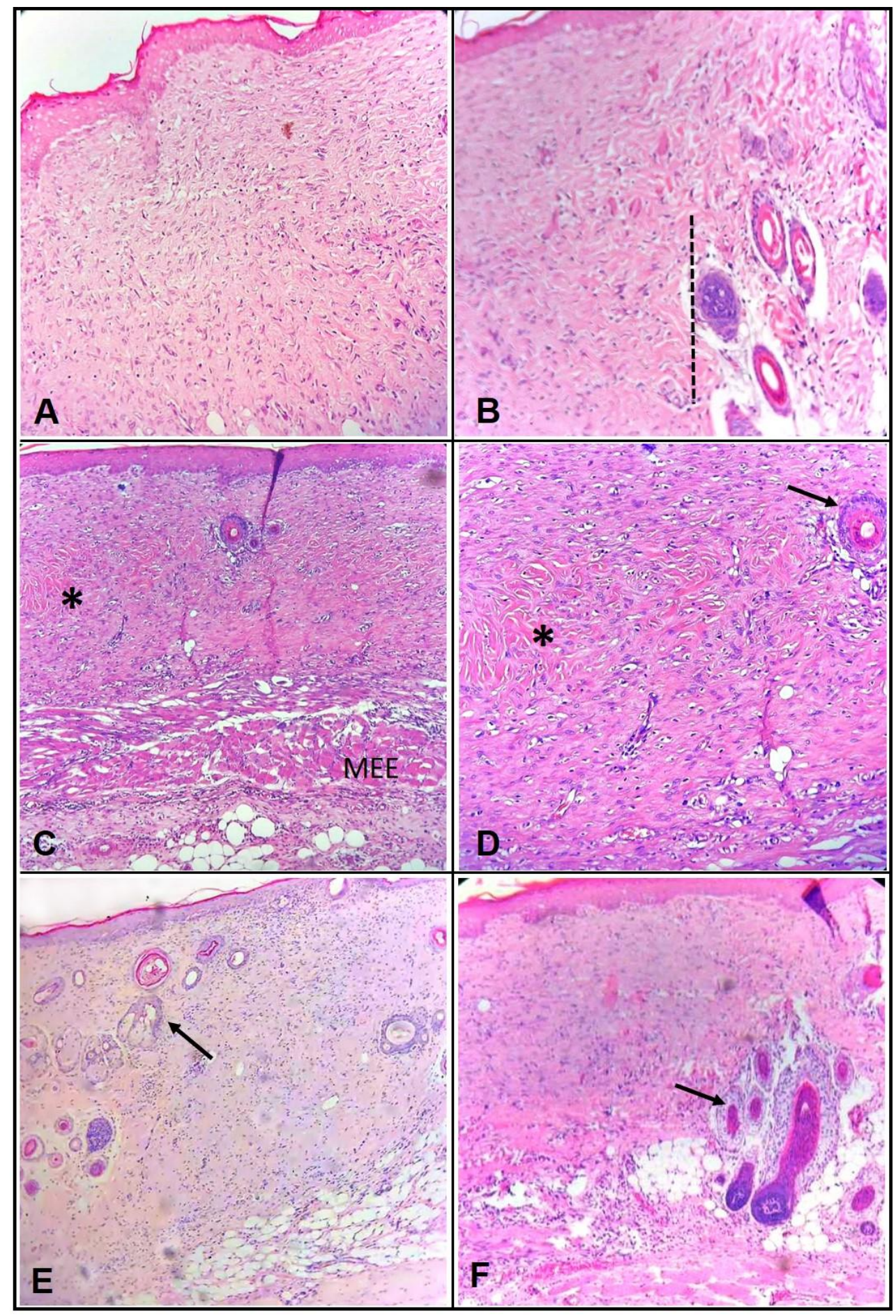

Figure 3. Third-degree burn injuries in rats. Photomicrograph with HE staining. A and B - GC 15 days showing complete epithelialization with loose connective tissue and site outside the lesion with normal skin (dotted line), 20x; C and D - LBP group 15 days showing complete re-epithelialization with loose connective tissue, the onset of formation of dense non-modeled connective tissue (asterisk) and hair follicle (black arrow), 20x; E - GC 21 days, formation of epithelial attachments such as hair follicles and sebaceous glands (black arrow) 20x; F - LBP Group 21 days, formation of hair follicles and sebaceous glands (black arrow) and greater organization of the dermis, 20x.

Figure 2 shows a histological difference between the groups at 7 days (D - control group; E and F - LBP group). The therapy promoted an increase in neovascularization, greater infiltration of pro-inflammatory cells, and increased fibroblasts and greater deposition of the 
extracellular matrix. These results show that lesions treated with the laser have faster tissue repair compared to the control group.

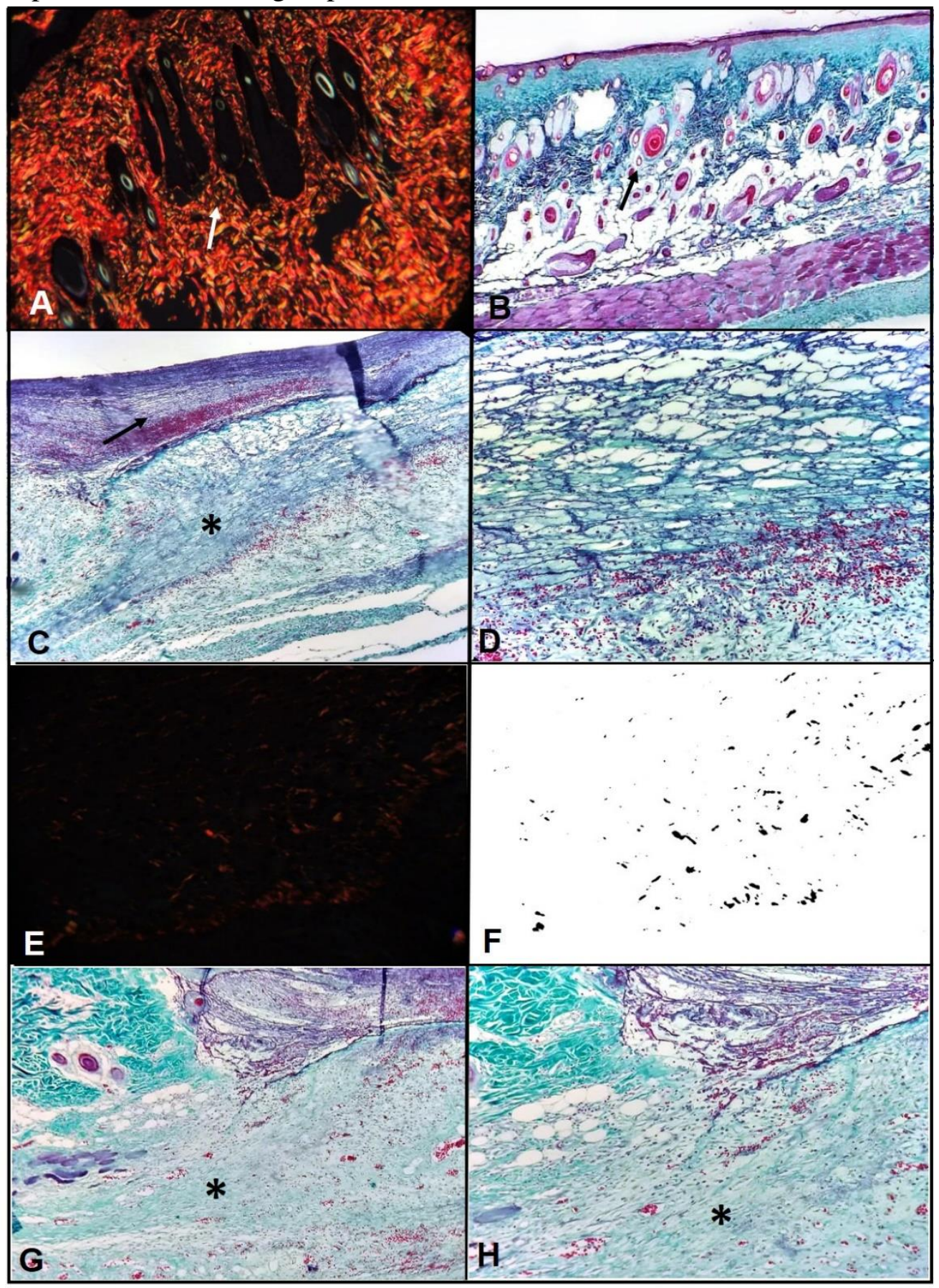

Figure 4. Histological photomicrograph of third-degree burn injuries in rats, by staining Picrosírius red and Gomori. A - Normal skin tissue stained with Picrosirius red. Type I collagen (yellow and red) and hair follicles on the white arrow, 20x; B - normal skin tissue stained with Gomori's trichrome. Connective tissue stained in shades of light and dark blue in the superficial and deep dermis and hair follicles in the black arrow; C - CG 3 days, presence of inflammatory infiltrate, hemorrhage (black arrow), edema with tissue disorganization and little evident collagen, 10x; D - same as C; E - GC 3 days, a small amount of type I collagen marked in red with Picrosirius red, 20x; F - GC 3 days, conversion of the mark in E to pixels in the Image J program; G - LBP 3 days, with intense inflammatory, infiltrate, hemorrhage (black arrow), area with edema, tissue disorganization and little evident collagen (asterisk), 10x; $\mathrm{H}$ - area described in $\mathrm{G}$ with 20x.

In Figure 3, A and B photomicrographs of the lesions in the control group at 15 days. C and D, LBP group at 15 days. Greater organization of the dermis is observed in the treated group, with the beginning of the separation of the superficial and deep dermis indicated by the 
asterisk. E and F, control group and LBP, respectively, at 21 days, showing greater tissue organization and greater amount of hair follicles in the treated group compared to the control group, showing that the repair process was faster and more efficient with the intervention.

Regarding staining performed by the Gomori Trichrome technique, it allowed observing differences between the Laser Group (DL) and the Control Group (CG). From the 3rd day after the injury was induced, the samples showed improvement in the tissue repair process in the treated group compared to the $\mathrm{CG}$, with a slight increase in collagen deposition and a greater presence of fibroblasts (Figure 4). Regarding the microscopic parameters of the granulation tissue and organization of the extracellular matrix, there was a difference between the means of the 5 samples of each group as a function of score 1 . However, the analysis of fibroblasts showed an increase from 1.2 in the CG to 2.2 in the LBP, as shown in Table 3 and Graph 3.

Table 3. Histopathological evaluations by staining with Gomori trichrome in the control and LBP groups on days 3, 7, 15 and 21 after the burn injury in rats - mean values in score (0 to 4).

\begin{tabular}{|c|c|c|c|c|c|}
\hline PARAMETERS & & 03 days & 07 days & 15 days & 21 days \\
\hline \multirow[t]{2}{*}{ Granulation Tissue } & $\mathrm{GC}$ & $1^{\mathrm{Aa}}$ & $2^{\mathrm{ACa}}$ & $2.4^{\mathrm{ACa}}$ & $3.25^{\mathrm{BCa}}$ \\
\hline & LBP & $1^{\mathrm{Aa}}$ & $2.8^{\mathrm{ACa}}$ & $4^{\mathrm{BCa}}$ & $4^{\mathrm{BCa}}$ \\
\hline \multirow[t]{2}{*}{ Matrix Organization } & $\mathrm{GC}$ & $1^{\mathrm{Aa}}$ & $1^{\mathrm{ACa}}$ & $1.6^{\mathrm{ACa}}$ & $3^{\mathrm{BDa}}$ \\
\hline & LBP & $1^{\mathrm{Aa}}$ & $1.2^{\mathrm{ACa}}$ & $3.4^{\mathrm{BCa}}$ & $3.6^{\mathrm{BDa}}$ \\
\hline \multirow[t]{2}{*}{ Fibroblast } & GC & $1.2^{\mathrm{Aa}}$ & $1.8^{\mathrm{Aa}}$ & $3^{\mathrm{Aa}}$ & $3^{\mathrm{Aa}}$ \\
\hline & LBP & $2.2^{\mathrm{Aa}}$ & $3.2^{\mathrm{Aa}}$ & $3.4^{\mathrm{Aa}}$ & $3.6^{\mathrm{Aa}}$ \\
\hline
\end{tabular}

Note. Scores from 0 to 4, being: score 0: absent; score 1: up to 25\%; score 2: between 25 and 50\%; score 3: between $51 \%$ and $75 \%$; and score 4 : from $76 \%$ to $100 \%$. Different lower case letters in the same column for the same parameter indicate a significant difference between groups by the Kruskal-Wallis test $(\mathrm{p}<0.05)$. Different capital letters on the same line indicate the existence of a significant difference between the days in the group by the Kruskal-Wallis test $(\mathrm{p}<0.05)$.

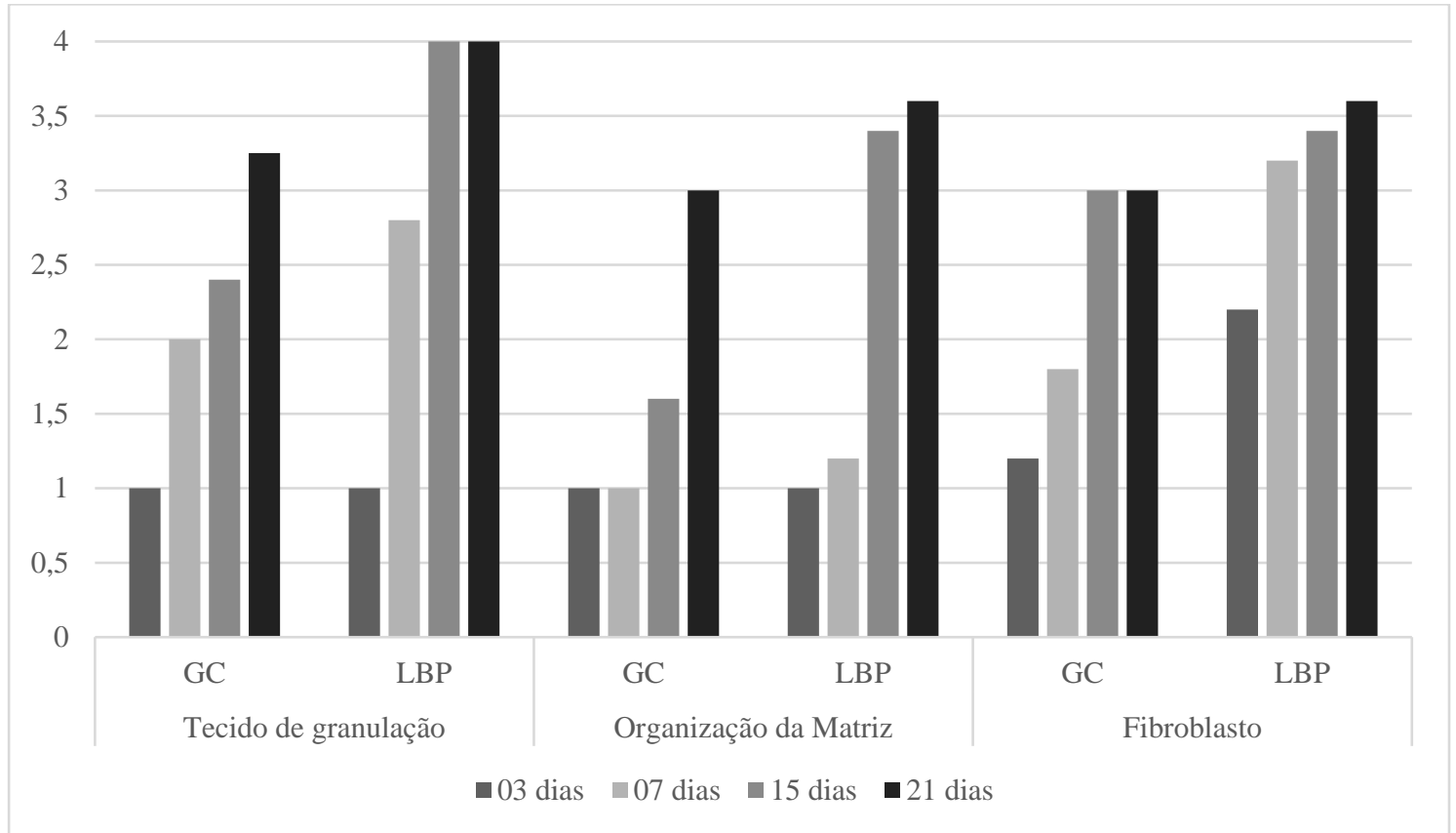

Chart 3. Semi-quantitative histological evaluation by staining with Gomori trichrome in third-degree burn injuries in rats. Scores from 0 to 4, being: score 0: absent; score 1: up to 25\%; score 2: between 25 and $50 \%$; score 3 : between $51 \%$ and $75 \%$; and score 4 : from $76 \%$ to $100 \%$.

As for the 7th day after the injury (Table 3), there was a difference, although not significant ( $p>0.05)$ in the analyzed parameters, showing an increase in the average of the 5 samples for the laser group in relation to the control group. The granulation tissue had a score 
of 2 in the GC and 2.8 in the LBP, in the organization of the extracellular matrix, there was an increase from 1 in the GC to 1.2 in the LBP and in the presence of fibroblasts increased from 1.8 in the GC to 3.2 in the LBP. Thus, it was possible to observe a better organization of the dermal connective tissue (Figure 5). There was no significant difference (p 0.05) in the statistical analysis between the groups on days 3 and 7 of the Tukey-Anova test and the paired T-test.

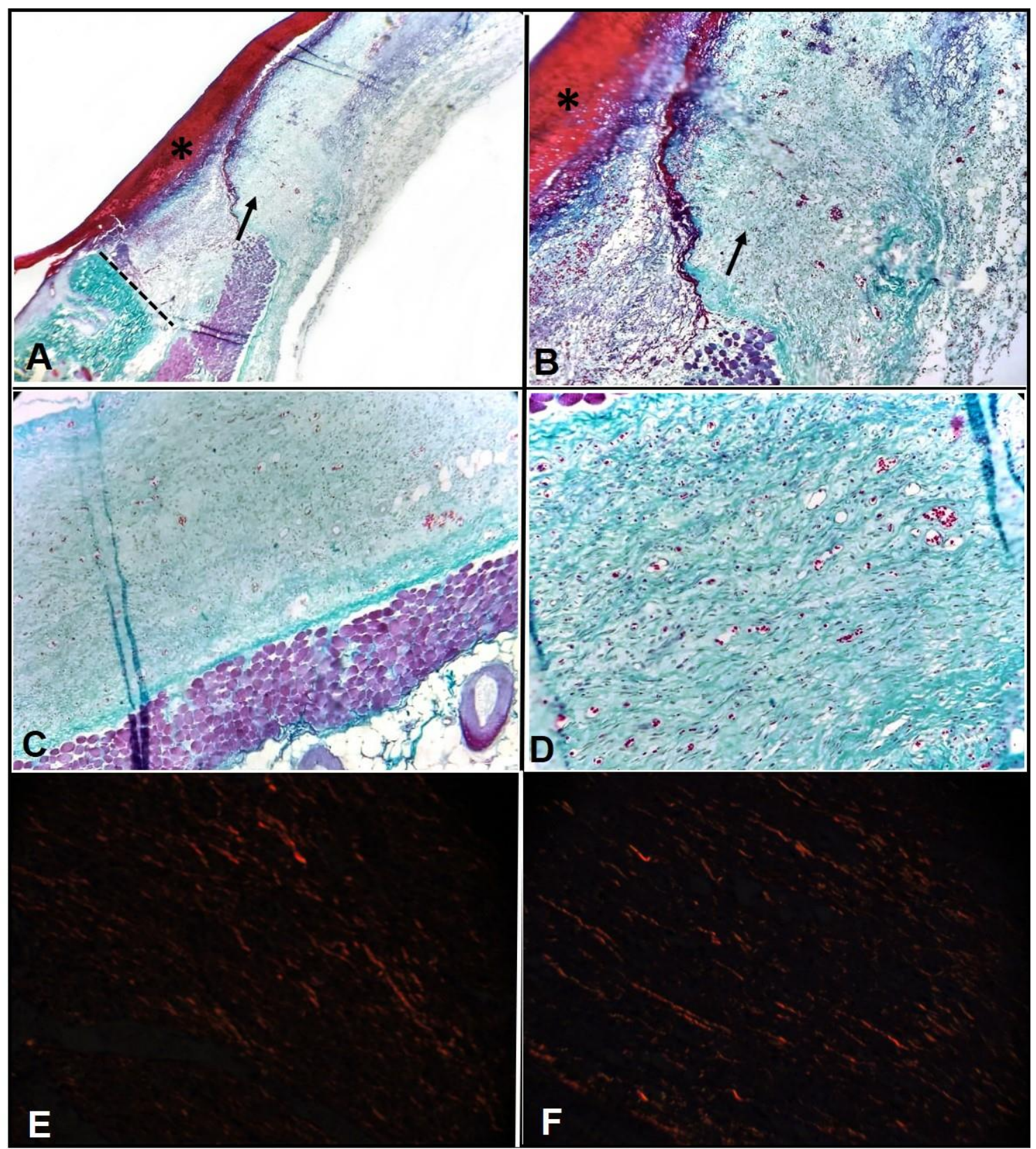

Figure 5. Skin lesion from third-degree burn 7 days. Photomicrography by Picrosírius red and Gomori staining. A - GC 7 days, an area with crust (asterisk) and area with beginning of tissue organization with loose connective tissue stained in light blue (black arrow) - (dotted line limit for an area without injury), 10x; B - area described in A with a 20x objective. C - LBP 7 days, there is an area with loose organized connective tissue stained in light blue and angiogenesis, 10x; D - area described in C with a 20x objective; E - GC 7 days, little type I collagen marked in red with Picrosirius red, 20x; F - LBP 7 days, little type I collagen marked in red with Picrosirius red, $20 x$.

On the 15th day after the injury, it was possible to observe, from the Gomori's Trichrome stain (Table and Graph 3), a difference in the formation of granulation tissue. The control group $(2,4)$ showed moderate formation, while the LBP group showed diffuse 
deposition of the tissue (4). Likewise, it occurred in relation to the extracellular matrix organization, with mild/moderate organization in the CG (1.6) and a marked organization (3.4) in the LBP group, more similar to the normal superficial and deep dermis.

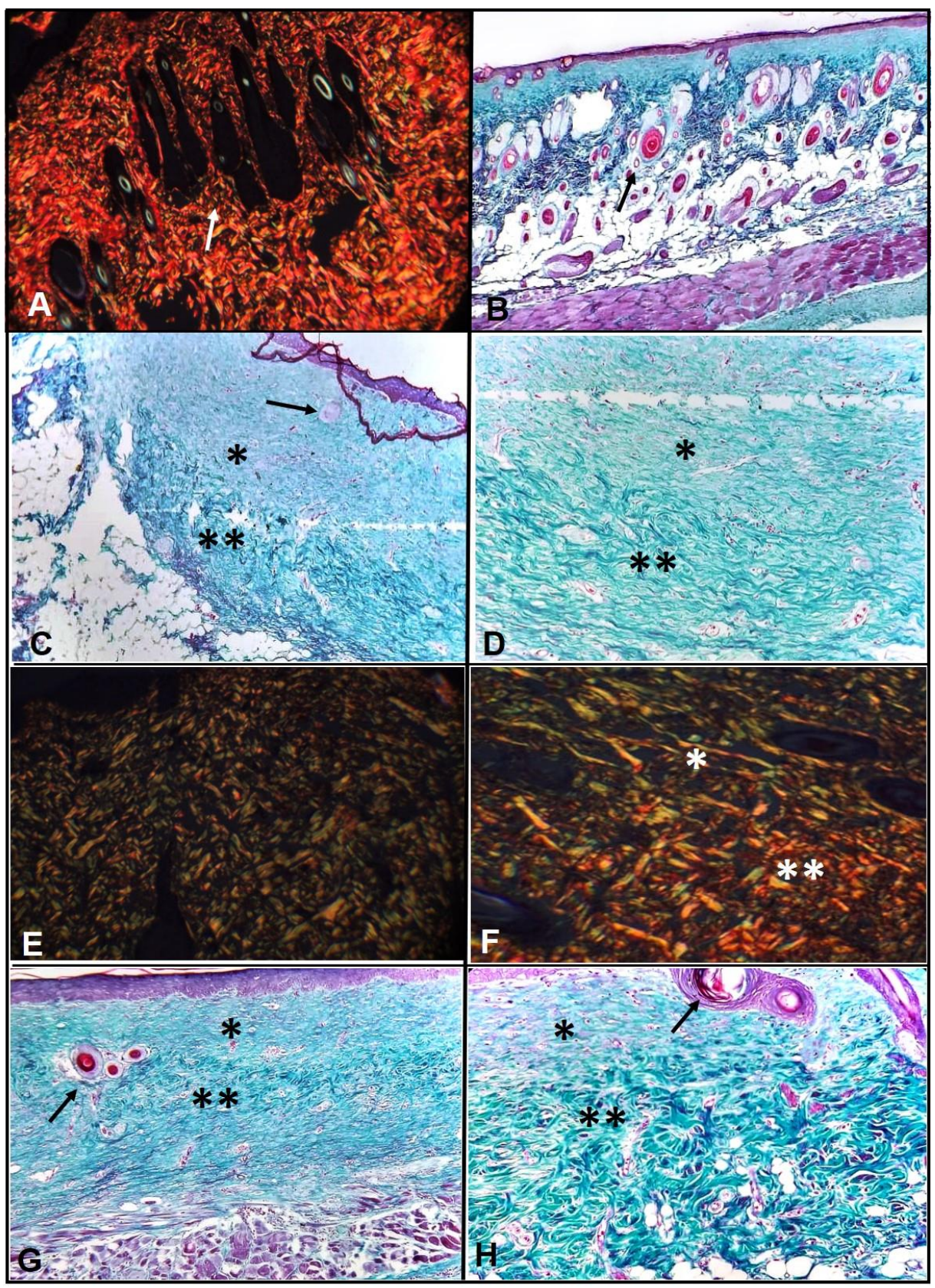

Figure 6. Skin lesions from third-degree burns in rats. Photomicrography by Picrosírius red and Gomori staining. A - Normal skin stained with Picrosirius red, type I collagen marked in yellow and red and hair follicles on the white arrow; B - normal skin stained with Gomori, connective tissue stained in shades of light and dark blue in the superficial and deep dermis and hair follicles in the black arrow; C - GC 15 days, superficial dermis

$(*)$ and deep dermis $(* *)$ with hair follicle formation (black arrow), 10x; D - area described in C with a 20x objective; E - GC 15 days, little type I collagen marked in red and more type III collagen marked in green with red Picrosirius, 20x; F - LBP 15 days, little type I collagen marked in red and more type III collagen marked in green, and beginning of demarcation of the superficial $(*)$ and deep $(* *)$ dermis, with red Picrosirius, 20x; G LBP 15 days, there is an area of the superficial $(*)$ and deep $(* *)$ dermis more organized with the formation of hair follicles with keratin (black arrow), 10x; $\mathrm{H}$ - area described in $\mathrm{G}$ with a 20x objective.

There was no statistical difference ( $p>0.05)$ in the presence of fibroblasts between groups and days, although histologically, the LBP group (3.4) showed a higher number of cells compared to the GC group (3). In the tissue remodeling phase, at 21 days after the injury, 
intense granulation tissue formation was observed (Table 3 and Graph 3 ) in the CG (3.25) with the maintenance of the diffuse form of the LBP group (4). The matrix organization was defined as intense in the CG (3) and intense/diffuse in the LBP group $(3,6)$, as well as the presence of fibroblasts in the GC (3) and in the LBP group $(3,6)$.

Although a histological difference was observed, the statistical tests (Tukey-Anova test and the paired T-test) did not show a level of significance ( $p>0.05)$ in the comparison between groups and days. However, histopathological images referring to these groups can be seen in Figures 6 and 7.

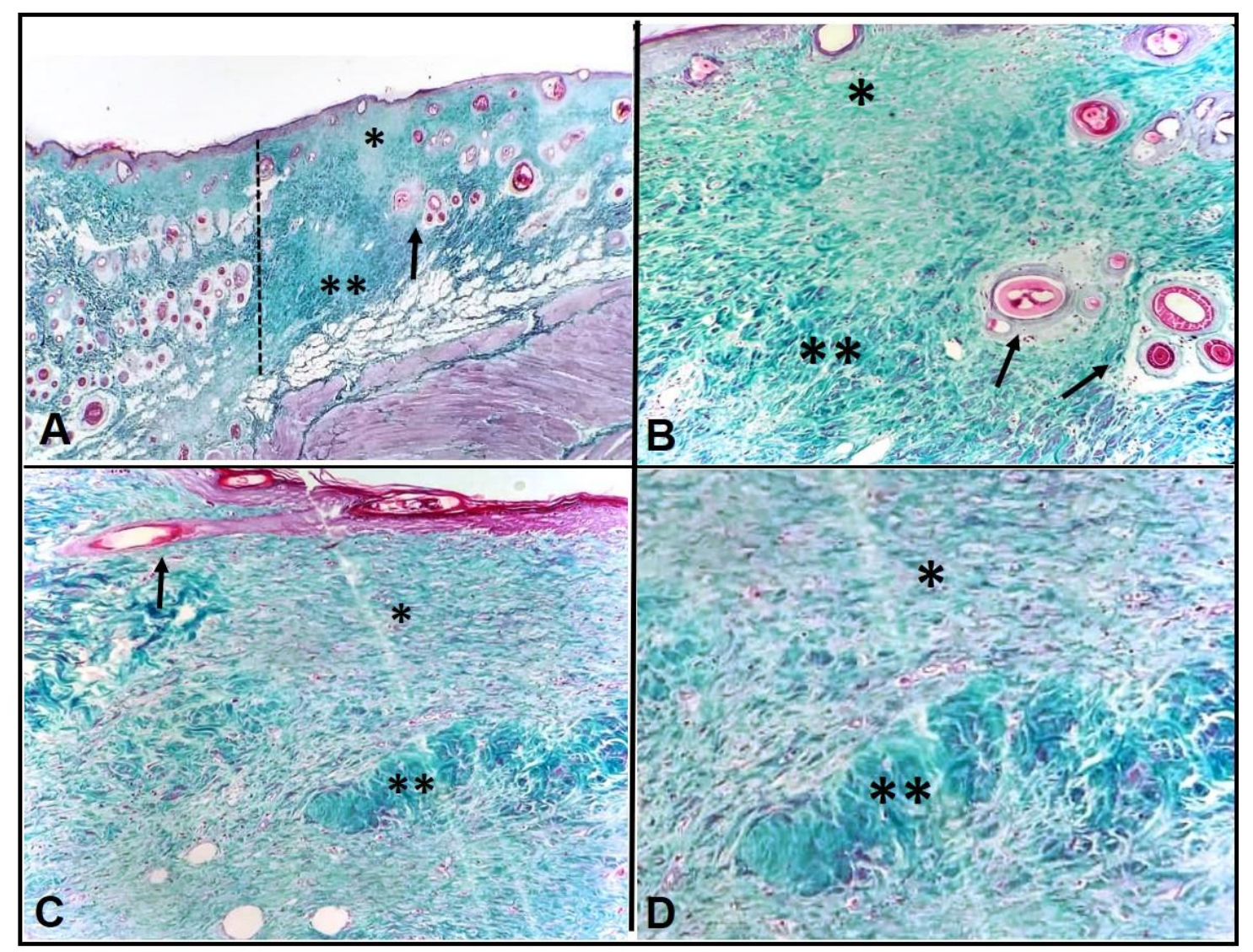

Figure 7. Photomicrograph of third-degree burn injuries in rats in groups of 21 days, by staining Picrosírius red and Trichrome Gomori. A: GC 21 days, there is an area of the superficial dermis (*) and deep dermis (**) with the formation of hair follicles (black arrow), (dotted line limit for the area without lesion, 10x; B: area described in A in 20x objective; C: LBP 21 days, there is an area of the superficial dermis (*) and deep dermis (**) with greater density and formation of hair follicles (black arrow); D: area described in C with a 20x objective.

The healing remodeling phase was evaluated by quantitative measurement of collagen in pixels determined from samples submitted to staining with Picrosirius red and analyzed by polarized light microscopy, as shown in Table 4 and Graph 4. On the 3rd day after lesion induction, it was possible to observe a decrease in the means between the five samples from 235.73 pixels in the CG to 155.746 in the LBP. In the biopsy time of 7 days, a lower quantification of pixels was observed in the CG (157.44) than the LBP group (154.39), showing less presence of type III collagen and greater maturation of the matrix more type I collagen. , although the statistical analysis using the Tukey-Anova test and the paired T-test between the groups (days 3 and 7) did not show any significant difference ( $p>0.05$ ). After 15 days of injury induction, it was possible to observe an average of 178,018 pixels in the CG and in the LBP group, an average of 213.154. On the 21st day, although there was no statistical difference between the groups and days, a greater average was observed in the LBP group of 153.207 pixels compared to the CG with an average of 145.484 pixels. 
Table 4. Average collagen quantification values, in pixels, by histopathological evaluations by Picrosirius red staining of the control and LBP groups on days 3, 7, 15, and 21 after the burn lesion in rats.

\begin{tabular}{c|c|c} 
& CONTROL GROUP & LBP GROUP \\
\hline 3 days & 235.73 pixels $^{\mathrm{Aa}}$ & 155.746 pixels $^{\mathrm{Aa}}$ \\
\hline 7 days & 157.44 pixels $^{\mathrm{Aa}}$ & 154.39 pixels $^{\mathrm{Aa}}$ \\
\hline 15 days & 178.018 pixels $^{\mathrm{Aa}}$ & 213.154 pixels $^{\mathrm{Aa}}$ \\
\hline 21 days & 145.484 pixels $^{\mathrm{Aa}}$ & 153.207 pixels $^{\mathrm{Aa}}$
\end{tabular}

Note. Different lower case letters in the same column indicate a significant difference between groups by a Tpaired test $(\mathrm{p}<0.05)$. Different capital letters on the same line indicate a significant difference between the days in the group by Tukey test $(\mathrm{p}<0.05)$.

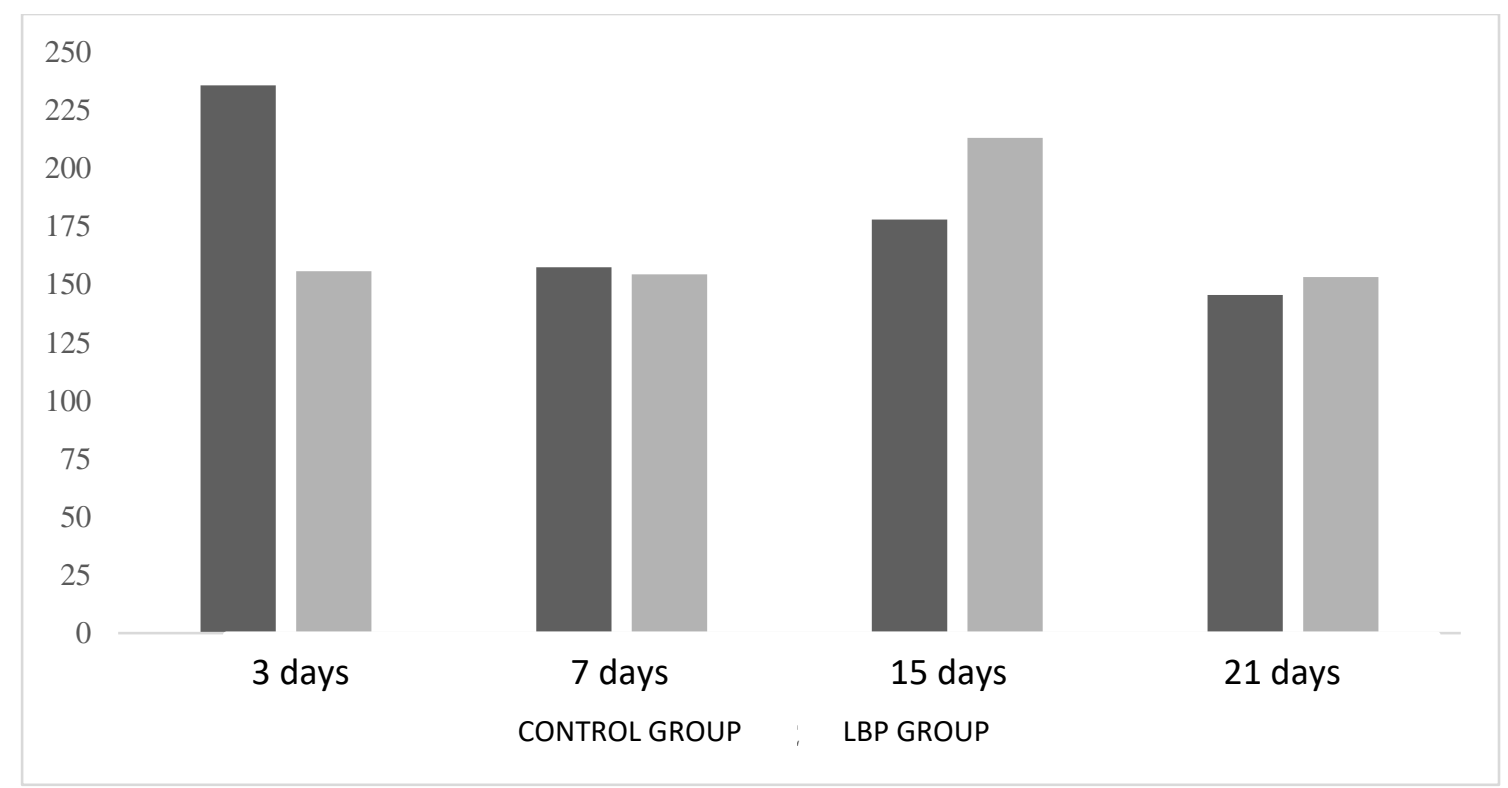

Chart 4. Quantification of collagen in pixels assessed by Picrosirius red staining in third-degree burn lesions in rats.

\subsection{Discussion.}

The mechanisms involved in the photobiomodulation effects are still being studied. One of the mechanisms described is the absorption of wavelengths by mitochondrial enzymes, such as cytochrome $\mathrm{C}$ oxides (CCO). The CCO stimulus produced by laser light increases the production of ATP and reactive oxygen species (EROS) in cells, inducing cell signaling to activate different biochemical pathways responsible for stimulating protein synthesis, enzymatic activation and cell proliferation [20].

The photobiomodulation effects also regulate cell membrane ion channels and stimulate cytokine synthesis, such as TGF- $\beta 20$, promote endothelial migration, greater angiogenesis, immunomodulation, increased matrix deposition by fibroblasts and accelerate wound contraction [20].

In this study's morphometric analysis, it is observed, mainly when observed on the 7th day, a more accelerated contraction of the wounds in the treated group in relation to the control group. Figure 1 shows an important difference in the size of the lesions at 7 days after induction. In the CG, there was less reduction in the lesion area compared to the treated group after 3 days. Gupta et al. [22] obtained similar results with a difference of $50 \%$ in the contraction of the lesion between the treated and control groups.

Although both groups were evaluated histologically by three slide staining methods, Gomori's Trichrome and Picrosirius red showed better collagen deposition and maturation and the organization of the extracellular matrix. The assessment of the degree of necrosis did not 
show any statistically significant difference between the two groups at any time during the study. Thus, it is concluded that although the therapeutic method did not reduce tissue necrosis, it did not aggravate it, it only contributed to the evolution of the granulation tissue repair and formation process, reducing the number of dead cells and accelerating the replacement by new ones.

The formation of crust and edema was more evident in the control group, demonstrating that the LBP was able to control better the exudative cellular processes that influence the production of these parameters. Greater angiogenesis was also observed in the treated group, allowing greater tissue drainage and greater edema reduction. In the analysis with a biopsy time of 3 days, intense polymorphonuclear inflammatory infiltrates observed in the treated group. The presence of cells with phagocytic function in the inflammatory phase is important for cleaning the tissue, phagocyting dead cells, damaged matrix and pathogens and foreign bodies that contaminate the wound. Thus, a greater amount of polymorphonuclear cells in the treated group allows the formation of a microenvironment capable of accelerating the proliferative phase [7].

Therefore, the early reduction of polymorphonuclear inflammatory cells and the presence of mononuclear cells in the treated group compared to the control group is expected. Thus, the immunomodulatory effects allow accelerating the tissue repair process, promoting an initially more intense inflammatory phase and the late inflammatory phase, and the repair phase earlier than expected.

These results were also described by Gupta et al. [22] and Jin et al. [23]. In his work, after the application of LBP, there was a reduction in the local inflammatory process. Several authors point to reducing pro-inflammatory cytokines, such as TNF- $\alpha$ and IL- 8 , as a possible control mechanism of the initial healing phase, favoring a better tissue repair. [1,9,22,23].

In addition, LBP is able to induce greater availability of growth factors and cytokines, such as VEGF, which would justify the occurrence of a more intense and rapid reepithelization in the treated group $[1,9,24]$. Corroborative, a greater proliferation of fibroblasts and angiogenesis was observed in the treated groups. The increase in neovascularization allows better oxygenation, tissue nutrition and recruitment of pro-inflammatory cells to the injury site. A greater number of cells, mainly macrophages and fibroblasts, act directly in the production and remodeling of the extracellular matrix, speeding up the closure of the wound and ensuring better organization of the tissue architecture [1,5,7].

The treated group showed a higher collagen deposition rate on days 3 and 7. As also reported by Fiório et al. [25]. In this study, greater deposition of type I collagen was observed in the treated group than in type III, which shows an earlier tissue maturation process.

In addition, histologically greater granulation tissue formation and organization of the extracellular matrix were observed 15 days after the induction of burns in the treated groups, compared to the control groups. These histological results demonstrate a rapid tissue organization stimulated by laser therapy. In addition, Picrosirius red staining demonstrated the maturation of collagen fibers in both groups. However, the treated group showed more accelerated maturation of type I collagen than in the control group.

In a systematic review of 17 studies, Ocon et al. [5] evaluated photobiomodulation's effects on third-degree burns in animal models. In this review, the authors concluded that laser photobiomodulation favors the healing process in chiropractics, although there are differences in results. The different results found can be justified by the various methods, such as ideal laser power and wavelength, application regime, and analysis types. 
As noted, the use of LBP promotes a reduction in the healing time, representing clinically shorter hospital stay and a decrease in costs, guaranteeing a better quality of life for patients. In addition, this therapy does not demonstrate systemic repercussions, which reduces contraindications. However, it is necessary to conduct clinical trials that prove and standardize the use of low-power lasers in humans.

The authors recognize that the definition of the laser parameters needs to be standardized to avoid the study's limitations. In this way, it will be possible to understand the parameters applied to laser light. In addition, the statistical analysis of biopsies contributed to a statistically significant difference between groups.

\section{Conclusions}

It was concluded that low-power laser photobiomodulation during the healing process of skin burns reduced the time to repair the wound, increased angiogenesis, deposition and collagen maturation, in addition to promoting better remodeling of the extracellular matrix. Thus, laser therapy was able to promote better macro and microscopic aspects of the lesions. However, further studies are needed to standardize the technique with different protocols and their effects.

\section{Funding}

M.R. has received research grants through National Council for Scientific and Technological Development (CNPq) scholarship from Brazil.

\section{Acknowledgments}

We thank the Coordination for the Improvement of Higher Education Personnel (CAPES) for the granting of a scholarship to the 1st author and the Federal University of Goiás for the financial support in the translation and publishing processes of the paper.

\section{Conflicts of Interest}

The authors declare no conflict of interest.

\section{References}

1. Lamaro-Cardoso, A.; Bachion, M. M.; Morais, J. M.; Fantinati, M. S.; Milhomem, A. C.; Almeida, V. L.; Vinaud, M. C.; Lino-Júnior, R. S. Photobiomodulation associated to cellular therapy improve wound healing of experimental full thickness burn wounds in rats. Journal of Photochemistry and Photobiology B: Biology 2019, 194, 174-182. https://doi.org/10.1016/j.jphotobiol.2019.04.003.

2. Keshri, G. K.; Kumar, G.; Sharma, M.; Bora, K.; Kumar, B.; Gupta, A. Photobiomodulation effects of pulsedNIR laser $(810 \mathrm{~nm})$ and LED $(808 \pm 3 \mathrm{~nm})$ with identical treatment regimen on burn wound healing: A quantitative label-free global proteomic approach. Journal of Photochemistry and Photobiology 2021, 6, 100024. https://doi.org/10.1016/j.jpap.2021.100024.

3. Rosenthal, A.; Kolli, H.; Israilevich, R.; Moy, R. Lasers for the prevention and treatment of hypertrophic scars: a review of the literature. Journal of Cosmetic and Laser Therapy 2020, 22, 115-125. https://doi.org/10.1080/14764172.2020.1783451

4. Oliveira, R. A.; Boson, L. L. B.; Portela, S. M. M.; Filho, A. L. M. M.; de Oliveira Santiago, D. Low-intensity LED therapy $(658 \mathrm{~nm})$ on burn healing: a series of cases. Lasers Med Sci 2018; 33, 729-735. https://doi.org/10.1007/s10103-017-2399-z.

5. Ocon, C. A.; de Carvalho, P. T. C.; dos Santos, S. A.; Serra, A. J.; Junior, E. C. P. L.; Caires, J. R.; de Oliveira, M. F. D. Effects and parameters of the photobiomodulation in experimental models of third-degree burn: 
systematic reviewanalysis. Brazilian Journal of Development 2020, 6, 47073-47093. https://doi.org/10.34117/bjdv6n7-371.

6. Chinta, M. S.; Foster, D. S.; Borrelli, M. R.; Shen, A. H.; Wan, D. C.; Longaker, M. T. Fibroblast Heterogeneity in and Its Implications for Plastic and Reconstructive Surgery: A Basic Science Review. Plastic and Reconstructive Surgery Global Open 2020, 8, e2927. https://doi.org/10.1097/GOX.0000000000002927.

7. Storer, M. A.; Miller, F. D. Cellular and molecular mechanisms that regulate mammalian digit tip regeneration. Open Biology 2020, 10, 200194. https://doi.org/10.1098/rsob.200194.

8. Fu, X.; Dong, J.; Wang, S.; Yan, M; Yao, M. Advances in the treatment of traumatic scars with laser, intense pulsed light, radiofrequency, and ultrasound. Burn Trauma 2019, 7. https://doi.org/10.1186/s41038-0180141-0.

9. Hamblin, M. R. Mechanisms and applications of the anti-inflammatory effects of photobiomodulation. AIMS Biophys 2017, 4, 337-361. https://doi.org/10.3934/biophy.2017.3.337.

10. Jing, G.; Zhao, Y.; Dong, F.; Zhang, P.; Ren, H.; Liu, J.; Liu, Y.; Yu, C.; Hu, J.; Bao, G.; Kang, H. Effects of different energy density low-level laser therapies for temporomandibular joint disorders patients: a systematic review and network meta-analysis of parallel randomized controlled trials. Lasers in Medical Science 2020, 1-8. https://doi.org/10.1007/s10103-020-03197-7.

11. Ferraresi, C.; Dos Santos, R. V.; Marques, G.; Zangrande, M.; Leonaldo, R.; Hamblin, M. R.; Bagnato, V. S.; Parizotto, N. A. Light Emitting Diode Therapy (Ledt) Before Matches Prevents Increase In Creatine Kinase With A Light Dose Response In Volleyball Players. Lasers In Medical Science 2015; 30, 1281-1287. https://doi.org/10.1007/s10103-015-1728-3.

12. Zhao, H.; Hu, J.; Zhao, L. The effect of low-level laser therapy as an adjunct to periodontal surgery in the management of postoperative pain and wound healing: a systematic review and meta-analysis. Lasers in Medical Science 2021, 36, 175-187. https://doi.org/10.1007/s10103-020-03072-5.

13. Pereira, F. L. C.; Ferreira, M. V. L.; da Silva Mendes, P.; Rossi, F. M.; Alves, M. P.; Alves, B. L. P. Use of a High-Power Laser for Wound Healing: A Case Report. Journal of lasers in medical sciences 2020, 11, 112. https://doi.org/10.15171/jlms.2020.19.

14. Higuchi, A.; Wang, C. T.; Ling, Q. D.; Lee, H. H. C.; Kumar, S. S.; Chang, Y.; Alarfaj, A. A.; Munusamy, M. A.; Hsu, S. T.; Wu, G. J.; Umezawa, A. Hybrid-Membrane Migration Method to Isolate High-Purity Adipose-Derived Stem Cells from Fat Tissues. Scientific Reports 2015; 5. https://doi.org/10.1038/srep10217.

15. de Lima, V. H. S.; de Oliveira-Neto, O. B.; da Hora Sales, P. H.; da Silva Torres, T.; de Lima, F. J. C. Effectiveness of low-level laser therapy for oral mucositis prevention in patients undergoing chemoradiotherapy for the treatment of head and neck cancer: A systematic review and meta-analysis. Oral oncology 2020, 102, 104524. https://doi.org/10.1016/j.oraloncology.2019.104524.

16. Koo, H. M.; Yong, M. S.; Na, S. S. The effect off low-intensity laser theraphy (LILT) on cutaneous wound healing and pain relief in rats. $J$ Phys Ther Sci 2015, 27, 3421-3423. https://doi.org/10.1589/jpts.27.3421.

17. Goulart, C. P.; Otto, G.; Lima, N.; Neves, M.; Guimarães, A. T. B.; Bertolini, G. R. F. Efeitos adversos da eletrotermofototerapia em clínicas da cidade de Cascavel-PR. Fisioterapia e Pesquisa 2018, 25, 382-387. https://doi.org/10.1590/1809-2950/17001725042018.

18. Prabhu, V.; Rao, B. S. S.; Rao, A. C. K.; Prasad, K.; Mahato, K. K. Photobiomodulation invigorating collagen deposition, proliferating cell nuclear antigen and Ki67 expression during dermal wound repair in mice. Lasers in Medical Science 2020, 1-10. https://doi.org/10.1007/s10103-020-03202-z.

19. Tacon, K. C. B.; Santos, H. C. O.; Parente, L. M. L.; Cunha, L. C. D.; Lino-Júnior, R. D. S.; Ribeiro-Rotta, R. F., Tacon, F. S. de A.; Amaral, W. N. D.Atividade cicatrizante do laser AlGaInP (660nm) em ratos. Acta Cirurgica Brasileira 2011, 26, 373-378. https://doi.org/10.1590/S0102-86502011000500008.

20. Mosca, R. C.; Ong, A. A.; Albasha, O.; Bass, K.; Arany, P. Photobiomodulation therapy for wound care: a potent, noninvasive, photoceutical approach. Advances in skin \& wound care 2019, 32, 157-167. https://doi.org/10.1097/01.ASW.0000553600.97572.d2.

21. Kawano, T.; Takahashi, T.; Kaminaga, S.; Kadono, T.; Yamanaka, D.; Iwata, H.; Eguchi, S.; . A comparison of midazolam and dexmedetomidine for the recovery of serotonin syndrome in rats. Journal of anesthesia 2015, 29, 631-634. https://doi.org/10.1007/s00540-014-1973-9.

22. Gupta, A.; Keshri, G. K.; Yadav, A.; Gola, S.; Chauhan, S.; Salhan, A. K.; Bala Singh, S. Superpulsed (GaAs, $904 \mathrm{~nm}$ ) low-level laser therapy (LLLT) attenuates inflammatory response and enhances healing of burn wounds. Journal of biophotonics 2015, 8, 489-501. https://doi.org/10.1002/jbio.201400058. 
23. Jin, J.; Zheng, X.; He, F.; Zhang, Y.; Zhou, H.; Luo, P.; Hu, X.; Therapeutic efficacy of early photobiomodulation therapy on the zones of stasis in burns: An experimental rat model study. Wound Repair and Regeneration 2018, 26, 426-436. https://doi.org/10.1111/wrr.12661.

24. Brassolatti, P.; Bossini, P. S.; Kido, H. W.; Oliveira, M. C. D.; Almeida-Lopes, L.; Zanardi, L. M.; Napolitano, M. A.; de Avó, L. R. da S.; Araújo-Moreira, F. M.; Parizotto, N. A. Photobiomodulation and bacterial cellulose membrane in the treatment of third-degree burns in rats. Journal of tissue viability 2018, 27, 249256. https://doi.org/10.1016/j.jtv.2018.10.001.

25. Fiório, F. B.; Albertini, R.; Leal-Junior, E. C. P.; de Carvalho, P. D. T. C. Effect of low-level laser therapy on types I and III collagen and inflammatory cells in rats with induced third-degree burns. Lasers in medical science 2014, 29, 313-319. 